\title{
Alterações na Cobertura do Solo em Teresina, Piauí, Brasil
}

\author{
Changes in Land Coverage in Teresina, Piauí, Brasil
}

\author{
Silvia Maria Santana Andrade Lima ${ }^{1}$ \\ Wilza Gomes Reis Lopes ${ }^{2}$ \\ Antonio Cardoso Façanha ${ }^{3}$
}

\begin{abstract}
Palavras-chave:
Expansão urbana

Imagens de satélite

Solos permeáveis e impermeáveis
\end{abstract}

\section{Keywords:}

Urban Expansion

Satellite Images

Permeable and

Impermeable Soils

\begin{abstract}
Resumo
No processo de expansão urbana destacam-se os impactos da perda de cobertura vegetal e da impermeabilização do solo, que representam elementos indicadores da qualidade ambiental urbana. Nas cidades que mantêm seu dinamismo e atratividade, o crescimento desordenado com acelerado processo de aumento populacional associado à ocupação de mais solos, pode ser um problema. Teresina, capital do Piauí, apresenta dificuldades como outras cidades brasileiras, marcada por uma expansão urbana crescente e espraiada. Neste artigo tem-se como objetivo, analisar a expansão urbana e as mudanças na cobertura do solo, tendo como objeto de estudo a cidade de Teresina, Piauí, Brasil, considerando os anos de 2000, 2010 e 2015. Para o levantamento da cobertura do solo urbano, foram interpretadas imagens do satélite Landsat. No procedimento de Processamento Digital de Imagens (PDI) foi utilizado o software SPRING (5.1.8), Sistema para Processamento de Informações Georreferenciadas, produzido pelo Instituto Nacional de Pesquisas Espaciais (INPE). Enquanto para a geração de mapas temáticos, foi utilizado o software ArcGIS (10.3). A cidade de Teresina apresentou acelerado processo de expansão urbana, sem equilíbrio entre solos impermeabilizados e solos vegetados. A impermeabilização de vastas áreas de solo urbano em Teresina, somada às grandes perdas de sua cobertura vegetal, e a distribuição desigual da população e dos serviços básicos indicam que o processo de urbanização não está acontecendo de forma sustentável.
\end{abstract}

\footnotetext{
${ }^{1}$ Universidade Federal do Piauí - UFPI, Teresina, PI, Brasil. slima@ufpi.edu.br

2 Universidade Federal do Piauí - UFPI, Teresina, PI, Brasil. wilza@ufpi.edu.br

3 Universidade Federal do Piauí - UFPI, Teresina, PI, Brasil. facanha@ufpi.edu.br
} 


\section{INTRODUÇÃO}

O avanço da urbanização sobre os espaços naturais, em que a cidade se expande de forma rarefeita, apresenta muitas vezes, uma distribuição desigual da população nestes espaços, com zonas pobres e ricas, áreas carentes e outras bem servidas de equipamentos, trazendo como consequência desta expansão desordenada, gastos excessivos com infraestrutura urbana, perda de espaços permeáveis e de vegetação natural.

A urbanização implica em mudanças do meio ambiente natural, cujo processo deve ser considerado em seus vários contextos geográficos e históricos. Segundo Catalán, Sauri e Serra (2008), as questões ligadas à sustentabilidade, organização e crescimento urbano devem levar em consideração outros sistemas, como as questões econômicas da atividade e da competitividade dos territórios, questões sociais, do acesso democrático à cidade e da segregação socioespacial, além de questões de governabilidade, ligadas à manutenção da estrutura da cidade.

No entanto, em termos de impactos ambientais, a expressão mais evidente é a redução da vegetação. Em áreas urbanas, a cobertura vegetal é o mais importante elemento indicador de alterações do equilíbrio ambiental e da qualidade ambiental (ZHOU; WANG, 2011; ZHAO et al., 2013).

As áreas verdes, são elementos importantes na redução da poluição, na proteção de nascentes e mananciais e ajudam na manutenção da biodiversidade. A vegetação age, ainda, no microclima urbano, contribuindo no controle da radiação solar, evapotranspiração, umidade, temperatura do ar, ação dos ventos e das chuvas, filtragem da poluição do ar e sombreamento (MACHADO; PEREIRA; ANDRADE, 2010; FEITOSA et al., 2011; STREGLIO; FERREIRA; OLIVEIRA, 2013).

Altunkasa et al. (2017) associam a presença das áreas verdes a benefícios como, purificação do ar, recarga de águas subterrâneas, prevenção de erosão, além de colaborarem na recreação. Para Zhaou e Wang (2011), além dos aspectos já citados, somam-se os prazeres estéticos e de lazer, que contribuem com o bem-estar físico e psicológico.

No processo de expansão urbana, outra ação importante associada à perda de cobertura vegetal é a impermeabilização do solo. Para Sperandelli, Dupas e Pons (2013) e Kemerich et al. (2014), o crescimento urbano implica no aumento de áreas impermeáveis, diminuindo o processo de infiltração, fazendo com que as águas das chuvas escoem mais rapidamente, aumentando as chances de inundações e levando à sedimentação de reservatórios e cursos d'água, o que pode implicar em queda da qualidade da água, estabilidade de terrenos e funcionamento do sistema hídrico.

Londe e Mendes (2014) destacam que as diferentes funções exercidas pela cobertura vegetal, seja ambiental, social ou psicológica, amenizam as consequências da urbanização e contribuem para dar qualidade ao espaço urbano, justificando sua permanência e estudos nessa área.

Área verde, espaço livre, cobertura vegetal são termos, muitas vezes, empregados como sinônimos. Neste estudo usou-se o termo solo vegetado ou cobertura vegetal, já que se pretendeu não fazer distinção entre o porte das plantas (herbáceas, arbustos ou arbórea), origem da vegetação (natural ou cultivada), ou seu domínio (se pública ou privada), proposto por Moura e Nucci (2008) e Machado; Pereira e Andrade (2010)

A retirada da vegetação associada à expansão urbana é comum na maioria das cidades brasileiras, como também tem ocorrido na cidade de Teresina, capital do estado do Piauí. Segundo Feitosa et al. (2011), a cidade vem perdendo cobertura vegetal, o que tem comprometido o sombreamento e o conforto térmico na sua área urbana. Para Lima, Lopes e Façanha (2017), Teresina tem apresentado crescimento acelerado, tanto da população como da área urbana, a partir de ocupação rarefeita e espraiada.

Em Teresina, no período mais quente, que vai de outubro a dezembro, as temperaturas máximas podem chegar à casa dos $40^{\circ} \mathrm{C}$, sendo considerada, de acordo com Andrade (2016, p. 16), "a época do ano mais emblemática para a cidade, devido às condições atmosféricas favoráveis ao incremento das elevadas temperaturas e aumento do desconforto térmico humano". Ressalta-se que a presença de vegetação em locais de clima seco e quente, é fator primordial para a melhoria do conforto ambiental (ROCHA; NUCCI, 2019). Dessa forma, justifica-se a necessidade da presença de áreas com vegetação.

Neste artigo, tem-se como objetivo, analisar a expansão urbana e as mudanças na cobertura do solo, na cidade de Teresina, Piauí, considerando os anos de 2000, 2010 e 2015. 


\section{METODOLOGIA}

O município de Teresina concentra mais de um quarto da população do Estado, com estimativa de 868.0755 habitantes, para 2020, tendo crescimento acumulado de $18,02 \%$, entre os anos de 2000 e 2015, apresentando área territorial de $1.391,046 \mathrm{~km}^{2}$ (IBGE, 2020).

A capital piauiense apresenta clima tropical, dos mais quentes do Brasil e sub-úmido. As temperaturas registradas são elevadas, variando entre $22,0^{\circ} \mathrm{C}$ e $40,0^{\circ} \mathrm{C}$. Tem distribuição de chuvas bastante irregular, com média anual de $1332 \mathrm{~mm}$, concentradas, principalmente, no período chuvoso, que vai de dezembro a maio. Os meses de agosto a novembro, são os meses de atmosfera mais seca (TERESINA, 2010).

Teresina tem uma vegetação de domínio morfoclimático de transição do cerrado, caatinga e amazônico. Para Andrade (2016, p. 409), o município é repleto de "ilhas de paisagens", que abrangem matas de cocais, caatinga, alternados com cerrado e florestas. Está localizada nas coordenadas geográficas latitude $05^{\circ} 05^{\prime} 20^{\prime \prime} \mathrm{S}$ e longitude $42^{\circ} 48^{\circ} 07^{\prime \prime} \mathrm{W}$, com médias de altitude de 72 metros acima do nível do mar. Está situada às margens do rio Parnaíba, que separa o Piauí do estado do Maranhão, sendo cortada também pelo rio Poti. É a única capital na região Nordeste que não fica no litoral, distando 366 $\mathrm{km}$ da costa litorânea.

Teresina mais os municípios de Altos, Beneditinos, Coivaras, Curralinhos, Demerval Lobão, José de Freitas, Lagoa Alegre, Lagoa do Piaú, Miguel Leão, Monsenhor Gil, União, Pau D'arco do Piauí e Nazária, no Estado do Piauí, além de Timon, no Estado do Maranhão formam a Região Integrada de Desenvolvimento (RIDE) da Grande Teresina (Figura 1), criada pelo Decreto-Lei $\mathrm{n}^{\circ}$ 4.367, de 9 de setembro de 2002 (BRASIL, 2002).

Figura 1 - Mapa Localização Teresina

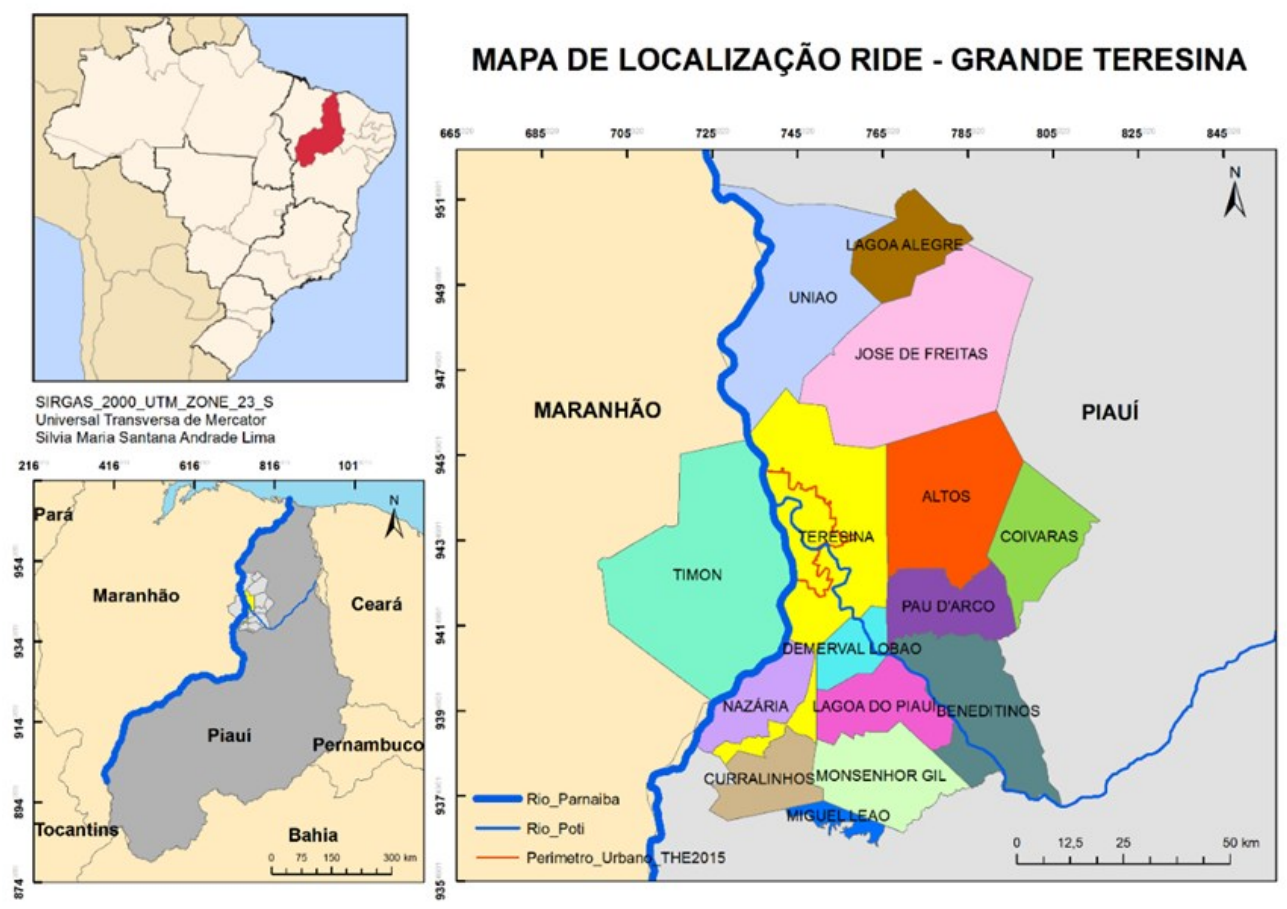

Fonte: Malha Digital Setores Censitários, IBGE (2010c)

Para o levantamento da cobertura do solo urbano foram usadas imagens LANDSAT 7, sensor Thematic Mapper (TM), com resolução espacial de 30 metros e 7 bandas espectrais, $(2000,2010)$ e o LANDSAT 8 OLI (Operacional Terra Imager), com nove bandas multiespectrais com resolução espacial de 30 e 15 metros (SANTOS, 2013).

O procedimento de Processamento Digital de Imagens (PDI) foi realizado utilizando-se o software SPRING (5.1.8), Sistema para
Processamento de Informações Georreferenciadas, produzido pelo Instituto Nacional de Pesquisas Espaciais (INPE). E para a geração de mapas temáticos, foi utilizado o software ArcGIS (10.3).

As imagens foram obtidas, gratuitamente, pelo site do USGS (U S. Geological Survey Serviço Geológico dos Estados Unidos), com ortorretificação de sistema, por meio de projeção cartográfica UTM e Datum WGS84, reprojetadas para SIRGAS_2000_UTM. Foram 
adquiridas em formato escalas de cinza, das bandas espectrais $1,2,3,4,5$ e 7 , a partir do satélite Landsat 7 TM, para 2000 (28/08/2000) e para $2010(21 / 07 / 2010)$. E, também, das bandas $2,3,4,5,6$, e 7 , do satélite Landsat 8 OLI, para o ano de 2015 (25/10/2015).

Para se obter melhor resolução, foram selecionadas imagens do segundo semestre de cada ano estudado, período mais seco na região, com menor cobertura de nuvem, sendo duas cenas para cada, uma, na órbita/ponto 219/63 e, outra, na órbita/ponto 219/64, para abranger toda a zona urbana de Teresina, definida pelo último perímetro, Lei $\mathrm{n}^{\circ} 4.831$ de 2015 (TERESINA, 2015b).

Foi utilizado, também, o software Google Earth para comparar com as imagens de satélite alguns elementos que não estavam bem definidos. No Quadro 1 estão apresentadas as características das imagens adquiridas.

Quadro 1 - Características das imagens de satélites utilizadas

\begin{tabular}{|c|c|c|c|c|c|c|}
\hline & IMAGEM & $\begin{array}{c}\text { RESOLUÇÃ } \\
\text { O } \\
\text { ESPECTRAL }\end{array}$ & BANDAS & $\begin{array}{c}\text { RESOLUÇA } \\
\text { O ESPACIAL }\end{array}$ & DATA & $\begin{array}{c}\text { ÓRBITA } \\
\text { /PONTO }\end{array}$ \\
\hline 2000 & $\begin{array}{c}\text { LANDSAT 7, } \\
\text { Thematic Mapper (TM) }\end{array}$ & $\begin{array}{c}7 \text { bandas } \\
\text { espectrais }\end{array}$ & $\begin{array}{c}1,2,3,4,5 \text { e } 7 \\
\text { (RGB 5, 4, 3) }\end{array}$ & 30 metros & $28 / 08 / 2000$ & $\begin{array}{c}219 / 63 \mathrm{e} \\
219 / 64\end{array}$ \\
\hline 2010 & $\begin{array}{c}\text { LANDSAT 7, } \\
\text { Thematic Mapper (TM) }\end{array}$ & $\begin{array}{c}7 \text { bandas } \\
\text { espectrais }\end{array}$ & $\begin{array}{c}1,2,3,4,5 \text { e } 7 \\
\text { (RGB 5, 4, 3) }\end{array}$ & 30 metros & $21 / 07 / 2010$ & $\begin{array}{c}219 / 63 \mathrm{e} \\
219 / 64\end{array}$ \\
\hline 2015 & $\begin{array}{c}\text { LANDSAT 8 OLI, } \\
\text { Operacional Terra } \\
\text { Imager }\end{array}$ & $\begin{array}{c}9 \text { bandas } \\
\text { espectrais }\end{array}$ & $\begin{array}{c}2,3,4,5,6, \text { e } 7 \\
\text { (RGB 4, 5, 6) }\end{array}$ & $\begin{array}{c}30 \text { e } 15 \\
\text { metros }\end{array}$ & $25 / 10 / 2015$ & $\begin{array}{c}219 / 63 \mathrm{e} \\
219 / 64\end{array}$ \\
\hline
\end{tabular}

Fonte: Os autores.

Para se obter imagens de melhor qualidade, foi realizado tratamento, por meio do SPRING (5.1.8). A seguir, foi criado um banco de dados e inserido duas imagens para cada ano (órbita/ponto 219/63 e órbita/ponto 219/64), efetuando-se a fusão destas imagens. Finalmente, foi realizado o recorte das imagens, utilizando como base, o shapefile do limite do perímetro urbano de Teresina, para 2015, desenhado no CAD e georeferenciado, adquirido na Prefeitura Municipal de Teresina (TERESINA, 2015b), obtendo-se assim, somente a área de interesse para a análise.

Foram escolhidas as seguintes classes de cobertura de solo: Solo Vegetado, Solo Exposto, Corpos D’Água e Solo Urbanizado, que são indicadores importantes para visualizar a qualidade do meio ambiente urbano. Para melhor entendimento apresenta-se no Quadro 2, as classes e alvos de interesse, utilizados neste estudo.

Quadro 2 - Definição dos alvos de interesse

\begin{tabular}{|c|c|c|}
\hline & CLASSES & DESCRIÇÃO \\
\hline 1 & Solo Vegetado & $\begin{array}{c}\text { Regiões não desmatadas com Vegetação densa, de médio porte e/ou } \\
\text { Vegetação rasteira }\end{array}$ \\
\hline 2 & Solo Exposto & Área livre de edificação com ausência de cobertura vegetal. \\
\hline 3 & Corpos d'água & Rios e lagoas. \\
\hline 4 & Solo Urbanizado & $\begin{array}{c}\text { Asfalto, calçamento, telhado cerâmico, telhado metálico, área } \\
\text { edificada. }\end{array}$ \\
\hline
\end{tabular}

Fonte: Os autores.

Para o mapeamento das áreas de interesse foi utilizado o método de Classificação Supervisionado, que consiste na extração de informação de imagens para reconhecer padrões e objetos homogêneos, a partir de dados que permitam a identificação de uma classe de interesse. Para melhor distinção dos elementos de interesse foi feita uma composição com filtro de cores RGB (RED, GREEN, BLUE) com as bandas espectrais 5, 4, 3 para o ano de 2000 e 2010, e bandas 4, 5, 6 para o ano de 2015, gerando uma composição falsa-cor. Ou seja, são imagens coloridas artificialmente ressaltando as mudanças observadas (MORATO et al., 2011).

Com as categorias definidas para a classificação, foi promovido um primeiro teste supervisionado, selecionando pequenas amostras homogêneas representativas de cada classe, para que não ocorresse confusão entre elas. Para analisar a qualidade das amostras adquiridas, verificando a matriz de erros de classificação, foi utilizado o Classificador 
MAXVER (Máxima Verossimilhança), que considera a ponderação das distâncias entre média dos níveis digitais das classes, utilizando parâmetros estatísticos. Avaliando o desempenho médio geral da classificação, foi possível dizer que as amostras se apresentaram satisfatórias, pois apontaram desempenho superior a $93 \%$.

O processo de classificação resultou na quantificação de valores associados às classes analisadas em hectare, que proporcionou os resultados na área territorial estudada, referentes às classes de Solo Vegetado, Solo Exposto, Corpos D’Água e Solo Urbanizado.

Além da classificação, também foi usada a segmentação dos dados entre regiões. As regiões foram classificadas de acordo com a distribuição das manchas consolidadas em relação aos pontos cardeais e, em cada região, entre o núcleo inicial (polígono urbano representando situação encontrada em 2000) e depois, nesta mesma área territorial, em 2010 e 2015, como proposto por Inostroza, Baur e Csaplovics (2013).

Foram divididas e consideradas, para análise, sete regiões denominadas Central, Sul,
Extremo Sul, Sudeste, Leste, Nordeste e Norte, que diferem da atual divisão administrativa da Prefeitura de Teresina (Centro-Norte, Sul, Leste e Sudeste), já que a setorização administrativa não leva em conta a continuidade das manchas urbanas e agrupa em uma mesma região administrativa espaços segmentados por vazios demográficos, ou ainda separados por vias expressas, ou divididos por rios.

\section{RESULTADOS E DISCUSSÃO}

A área territorial da cidade de Teresina, considerando o perímetro de 2015, definido pela Lei $\mathrm{n}^{\circ} 4.831$ (TERESINA, 2015b), apresentou perda de $31,38 \%$ de solos permeáveis (solos vegetados e solos expostos) entre 2000 e 2015 . A área permeável que abrangia, em 2000, 72,18 \% do território urbano reduziu para $49,52 \%$, em 2015 , e os solos impermeabilizados (solos urbanizados) cresceram na ordem de 86,74\%.

Tabela 1 - Categorias de Cobertura do Solo, em hectare e porcentagem da área urbana ocupada, para 2000,2010 e 2015.

\begin{tabular}{|c|c|c|c|c|c|c|}
\hline \multirow[b]{2}{*}{ TERESINA } & \multicolumn{3}{|c|}{ ÁREA EM HECTARE } & \multicolumn{3}{|c|}{ PERCENTUAL ÁREA } \\
\hline & 2000 & 2010 & 2015 & $\%$ em 2000 & $\begin{array}{c}\% \text { em } \\
2010\end{array}$ & $\%$ em 2015 \\
\hline Solo Urbanizado & $7.003,08$ & $10.759,68$ & $13.077,45$ & 26,45 & 40,64 & 49,39 \\
\hline Solo Vegetado & $17.293,59$ & $13.681,00$ & $10.046,34$ & 65,32 & 51,68 & 37,94 \\
\hline Solo Exposto & $1.815,75$ & $1.646,10$ & $3.065,22$ & 6,86 & 6,22 & 11,58 \\
\hline Rios e Lagoas & 363,33 & 387,99 & 286,74 & 1,37 & 1,46 & 1,09 \\
\hline TOTAL & & $26.475,75$ & & & $100 \%$ & \\
\hline
\end{tabular}

Fonte: Dados Imagens LANDSAT 7_TM e LANDSAT 8_OLI, USGS; TERESINA (2015a), processados pelo SPRING e ArcGIS (10.3).

Ao se comparar o crescimento populacional de Teresina, entre 2000 e 2010, e, também, entre 2000 e 2015 (IBGE, 2010a; IBGE, 2015), observa-se que as áreas urbanizadas aumentaram em maior proporção que o número de habitantes. A taxa de crescimento populacional, em dez anos (2000-2010), foi de $13,30 \%$, e os solos urbanizados aumentaram $53,64 \%$. Ainda, se for considerado o período de 15 anos (2000-2015), o crescimento demográfico ficou em torno de $18,02 \%$, e o crescimento de solos impermeabilizados foi de $86,74 \%$.

Constata-se que, dentre as classes e categorias trabalhadas, a que mais cresceu foi a parcela referente aos solos urbanizados, que de $26,45 \%$ de ocupação em 2000 , aumentou para $40,64 \%$ em 2010 . Em contrapartida, as maiores perdas são apresentadas na categoria de solos vegetados, que em 2000 cobriam $65,32 \%$ do território urbano, passando, em 2010, a cobrir apenas $51,68 \%$ deste território. O solo exposto entre 2000 e 2010 , passou de $6,86 \%$ para $6,22 \%$ da área total urbana. Vale ressaltar que a variação de solo exposto, representa perda da cobertura vegetal, ou ainda, indicar desmatamento para posterior ocupação por edificações.

Na Figura 2, é possível perceber claramente que o solo urbanizado foi a classe de solo que mais cresceu, enquanto a cobertura de solo com vegetação, foi o que apresentou maior queda, tendo este processo de perda se acelerado, principalmente, nos últimos cinco anos. 
Figura 2 - Categorias de cobertura do solo para Teresina 2000-2010-2015 em hectare

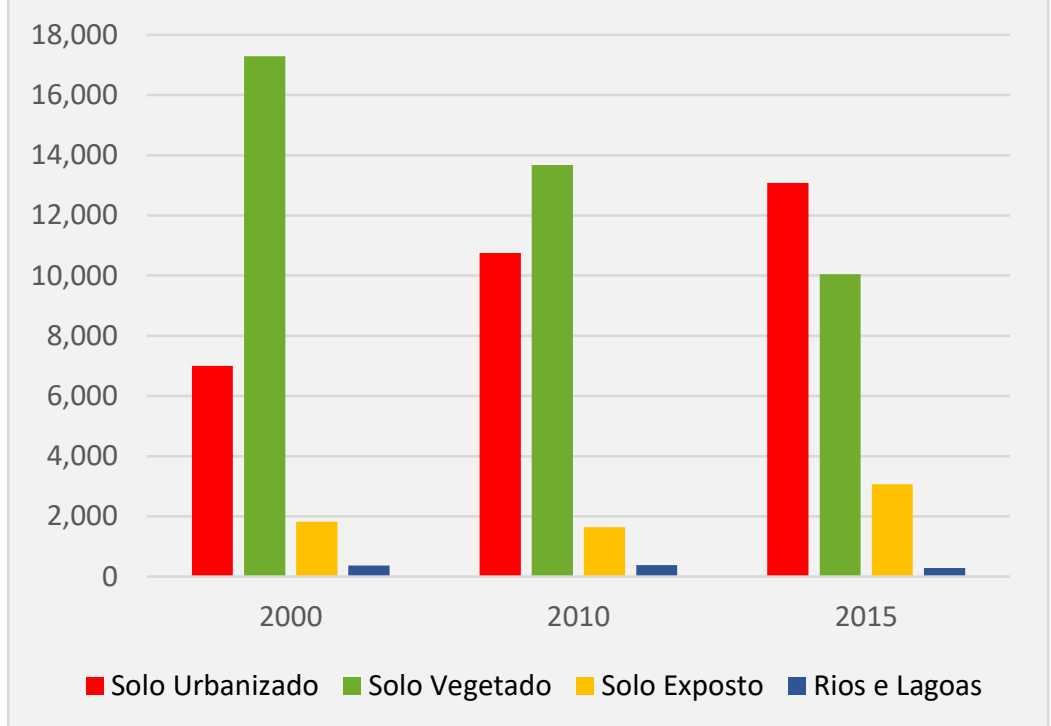

Fonte: Imagens LANDSAT 7_TM e LANDSAT 8_OLI, USGS (2000, 2010, 2015); TERESINA (2015a).

Os solos urbanizados, em 2000, cobriam $26,45 \%$ do território de Teresina e em 2015 , esta categoria de solo já representava $49,39 \%$ deste espaço. As áreas com cobertura vegetal equivaliam em 2000 , a $65,32 \%$ do território, e em 2015 , os solos vegetados representavam $37,94 \%$ do espaço urbano. A cobertura vegetal perdida, entre 2000 e 2010, é semelhante à perda entre 2010 e 2015, na metade do tempo, cinco anos. Outro dado relevante observado entre 2010 e 2015 , é o aumento de solo exposto, que de $6,22 \%$ passa a ocupar $11,58 \%$ da área urbana.

O elevado aumento no percentual de solo exposto e a queda na cobertura vegetal, entre 2010 e 2015, observado em Teresina, pode estar relacionado à implantação de novos loteamentos, já que um dos argumentos da Prefeitura Municipal para alterar o perímetro urbano (TERESINA, 2015b), foram as novas ocupações.

Em pesquisas anteriores sobre a zona urbana de Teresina, também foi constatada redução de sua cobertura vegetal. Machado, Pereira e Andrade (2010), identificaram perda de cobertura vegetal na ordem de $12,73 \%$, e $13 \mathrm{~km}^{2}$ (1.300,00 hectares), entre 2000 e 2006. Já Feitosa et al. (2011), observaram queda na cobertura vegetal de $29,69 \%$, correspondendo a perda aproximada de 48,3 $\mathrm{km}^{2} \quad(4.830,00$ hectares) de solo vegetado, no período entre 1989 e 2009. Nestas pesquisas, foram consideradas a área territorial urbana de 27.502,68 hectares referente ao perímetro de 2000 , e de $25.084,36$ hectares, para 2010. Também, foi considerada a área territorial do perímetro urbano, definida em 2015, que corresponde a 26.411,95 hectares.

A diferença existente nos perímetros estudados, além de dados de imagens, datas, satélites e resoluções diferentes, podem ter afetado os resultados, sendo, no entanto, importante ressaltar que todos os trabalhos apontaram para perdas e reduções na cobertura vegetal de Teresina, em decorrência da expansão urbana. Entre 2000 e 2015, foi constatado aumento de 6.074,37 hectares na cobertura com solo urbanizado, equivalente a $86,74 \%$ de crescimento, e a área de vegetação sofreu supressão de 7.247,25 hectares.

Foi observado que na cidade de Teresina já se encontra quase $50 \%$ de espaços impermeabilizados e menos de $40 \%$ de solos com cobertura vegetal. As mudanças na cobertura do solo urbano teresinense e sua espacialização podem ser visualizadas na Figura 3, para os anos de 2000 e 2010 e na Figura 4, para os anos de 2010 e 2015. 


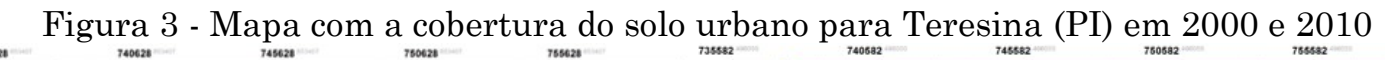
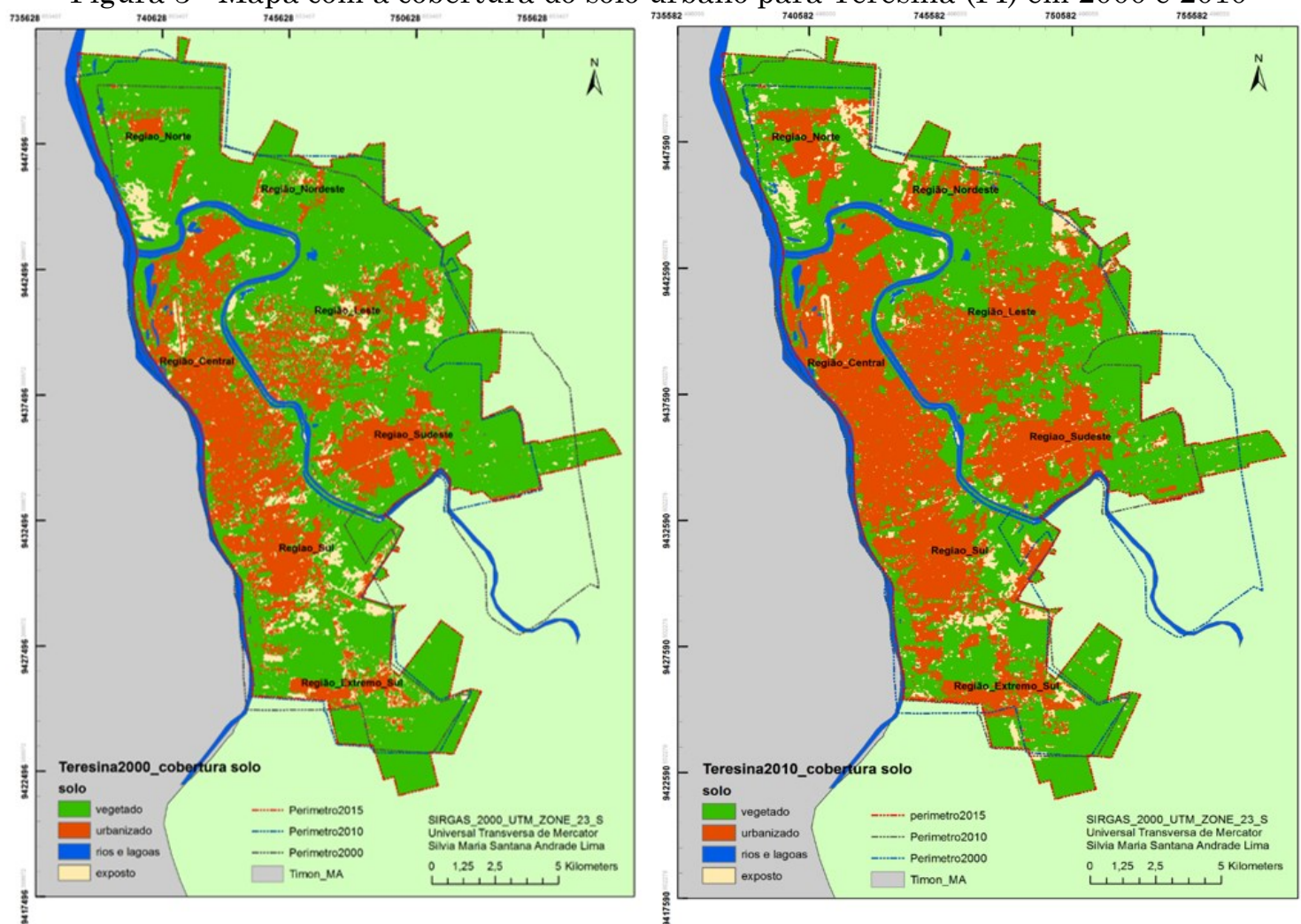

Fonte: Imagens LANDSAT 7_TM, USGS (2016); Malha dos Setores Censitários IBGE (2000c, 2010c) TERESINA (2015a), processadas no SPRING e ArcGIS (10.3).

Figura 4 - Mapa com a cobertura do solo urbano para Teresina-PI - 2010, 2015
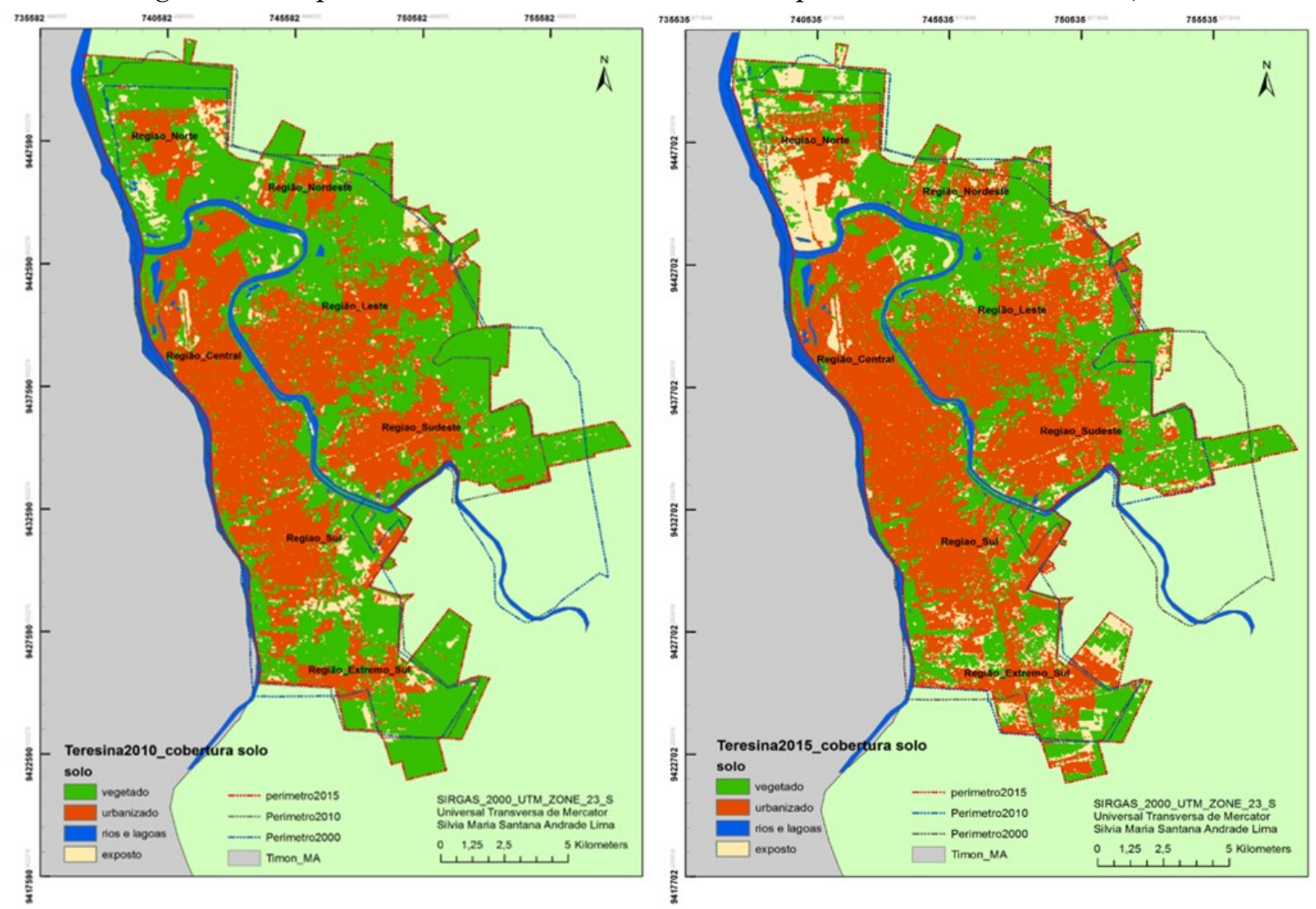

Fonte: Imagens LANDSAT 7_TM, USGS (2016); Malha dos Setores Censitários (IBGE, 2010c), TERESINA (2015a), processadas no SPRING e ArcGIS (10.3). 
As manchas urbanizadas contínuas, representadas pelos tons avermelhados, cresceram e tendem a se aglutinar, formando setores urbanos em torno da região Central, produzindo aglomerados bem definidos e distribuídos em regiões, Norte, Nordeste, Leste, Sudeste, Sul e Extremo Sul, separados por espaços vazios de edificações e urbanização, colocados em verde e tons claros. Assim, fica evidente que em Teresina, tem crescido a impermeabilização dos solos e reduzido a cobertura vegetal.

Todos os grupos de manchas urbanas, representados em vermelho, mostram solos vegetados e expostos entremeados no espaço urbanizado, percebidos pelos pontos em verde e em tons claros entre as manchas vermelhas. As manchas consolidadas com menores intercorrências de espaços vegetados, são observados na região Sudeste, e correspondem aos bairros Itararé, Parque Ideal, Renascença. Aspectos semelhantes também são vistos mais a norte da região Central, referente ao bairro Mocambinho.

Percebe-se que, em 2000 (Figura 3), Teresina apresentava manchas urbanas consolidadas em arranjos contínuos, distribuídos em setores em torno do espaço entre rios, região Central, com arranjos salteados e isolados ao Sul, formados pelos bairros Saci, Parque Piauí, Lourival Parente, Promorar, entre outros. No Extremo Sul, as áreas urbanizadas eram menores, destacando-se os bairros Angelim, Esplanada. Para além do rio Poti, tinha-se pequenas manchas de solos urbanizados a Norte, formados pelos bairros Santa Maria da Codipi, Parque Brasil, e a Nordeste, observava-se, apenas, o bairro Pedra Mole. Os demais grupos de manchas urbanas, que eram mais consolidadas, ficavam a Leste e Sudeste.

Em 2010 (Figuras 3 e 4), já se percebe o aumento das manchas avermelhadas ao Norte, a Nordeste e no Extremo Sul de Teresina, além do crescimento e consolidação das manchas urbanizadas na região Central, Leste e Sudeste. Nota-se que houve tendência de união entre as manchas urbanas avermelhadas e redução dos solos vegetados, em verde. É possível observar, ainda, que a cobertura vegetal, também, foi reduzida dentro da malha edificada consolidada, tornando-se menor a cada período estudado, 2010 e 2015 (Figura 4).

Constata-se que o crescimento e união entre as manchas urbanas se intensificaram em 2015 (Figura 4), percebendo-se ainda, certo isolamento das manchas avermelhadas ao Norte e a Nordeste, que continuaram cercadas de solo com cobertura vegetal. Nas demais regiões, houve tendência de expansão e união das áreas urbanizadas. Observa-se, ainda, que em 2015, houve aumento de solos expostos, representados em tons claros. Este quadro pode indicar um processo de desmatamento para novos loteamentos, como também, pode ser resultante dos baixos índices de chuva nos últimos anos, ou ainda, o aumento das queimadas nestas regiões, aspectos que afetam a cobertura do solo vegetado e exposto.

A perda de vegetação é mais representativa no entorno das manchas consolidadas, demonstrando o espraiamento da urbanização e maior expansão do solo edificado. $\mathrm{O}$ aumento da impermeabilização do solo é preocupante, pois como ressaltam Seto et al. (2011), implica em perda e perturbações de habitat de espécies, ou ainda, como enfatizam Garotti e Barbassa (2010) é um importante parâmetro para medir os impactos da urbanização.

Foi constatado que a região Leste, tem o espaço com maior preenchimento de áreas urbanizadas, dentro da mancha urbana consolidada, percebido mais claramente com a sobreposição dos solos construídos nos três períodos, 2000, 2010 e 2015 (Figura 5).

$\mathrm{Na}$ figura 5, é possível visualizar na região Leste, a presença de tons de amarelo, que representa a expansão em 2010, e tons de cinza, a expansão em 2015, dentro da mancha vermelha, que representa a situação da mancha urbana no ano 2000. Isto aponta maior ocupação dentro de sua mancha urbana. A região Leste é uma área bastante valorizada, procurada por população de maior poder aquisitivo, sendo, na visão de Reis Filho (2012), promissora para expansão e com grandes investimentos imobiliários, desde a década de 1970.

Constata-se, ainda, no ano de 2015, o maior crescimento de áreas localizadas ao Norte e no Extremo Sul de Teresina (Figura 5), marcadas pela presença de manchas cinzas. Já nas demais regiões, os tons cinzas estão mais presentes dentro das manchas vermelhas e amarelas do contexto urbano anterior (2000-2010). Isto aponta para o maior espraiamento nas regiões Norte, Extremo Sul e periferias. Nas demais regiões, além da ocupação de suas periferias, também, ocorreu a ocupação dos espaços intraurbanos. É possível, então, observar maior consumo de solo, mais impermeabilizações, mais espraiamento do que densificação, e consequentemente, maior perda de cobertura vegetal. 
Figura 5 - Mapa com a Evolução das Manchas Urbanas para Teresina 2000-2010-2015, segundo classificação de imagens da cobertura do solo urbano

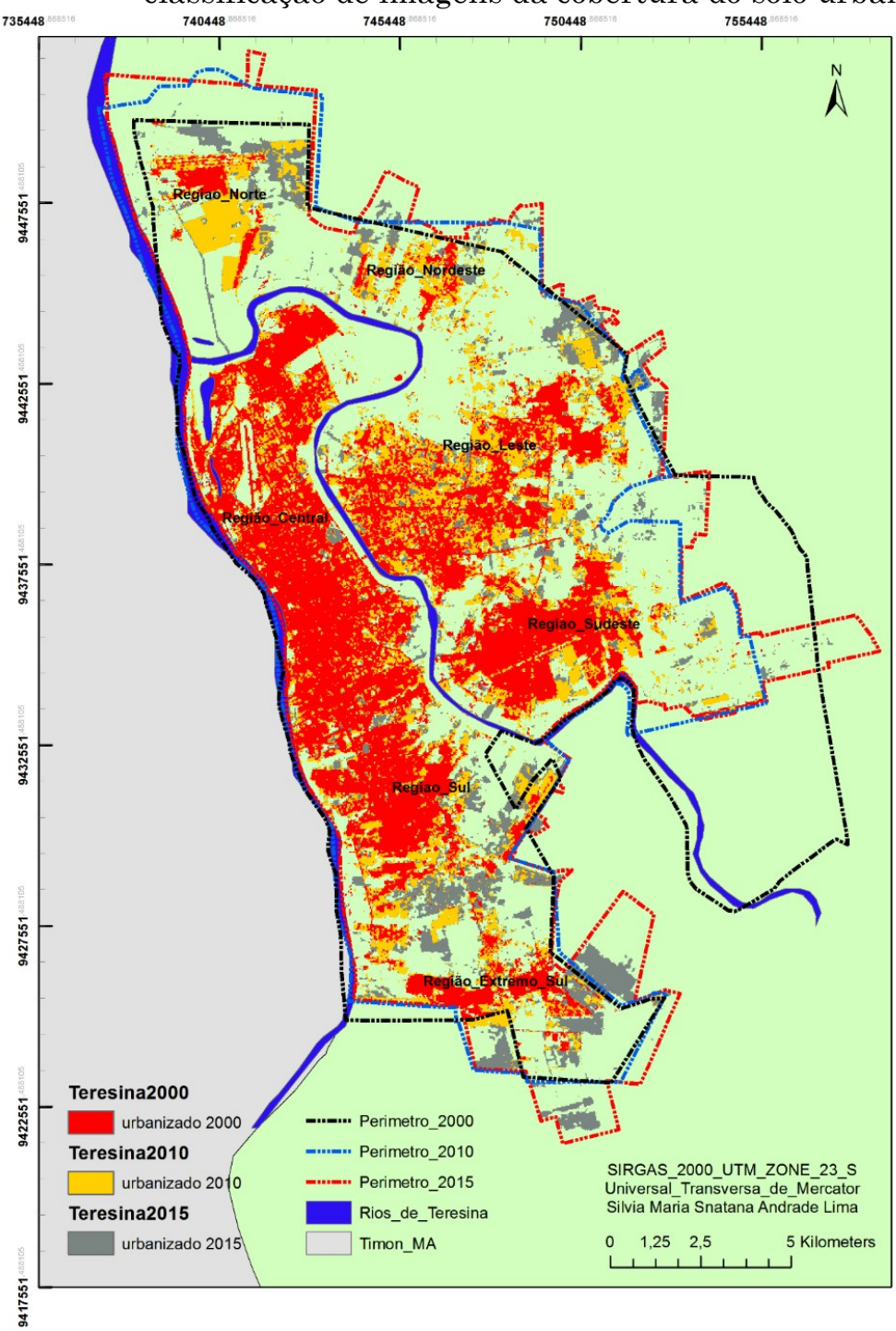

Fonte: Imagens LANDSAT 7_TM e LANDSAT 8_OLI, USGS (2000, 2010, 2015); Malha dos Setores Censitários (IBGE, 2010c), TERESINA (2015a), processados no SPRING e ArcGIS (10.3).

A observação dos índices de densidade populacional, nestas regiões, entre 2000 e 2010 , também reforça isto. A região do polígono Extremo Sul de Teresina é constituída, na sua grande maioria, de conjuntos habitacionais de baixa renda, Vilas (ocupações espontâneas sem infraestrutura) e Parques (conjuntos de casa com arruamento com mínimo de infraestrutura) (Teresina, 2017). Nela está localizado o Angelim, um dos maiores bairros em área territorial, originário de antiga fazenda de gado, transformada em área urbana em 1988. Neste bairro encontra-se a vila Irmã Dulce, uma das maiores ocupações registradas na cidade, datada de 1998, que, contava em 2010, com 14.222 habitantes (IBGE, 2010a).

Foi constatado, então, que este polígono foi o que mais reduziu sua densidade, passando de $69,43 \mathrm{hab} / \mathrm{ha}$ para $24,60 \mathrm{hab} / \mathrm{ha}$. No entanto, esta região mais ao sul de Teresina, foi a que mais ampliou seu território ocupado, de 250,14 hectares para $1.668,27$ hectares, explicando a queda na densidade.

Mascaró e Mascaró (2001), recomendam para as cidades médias brasileiras, um adensamento sem aumentar a demanda por infraestrutura, valores de densidade de $350 \mathrm{hab} / \mathrm{ha}$, no máximo, e mínimo de 40 hab/ha, embora, admitindo que não haja índices ideais.

Dessa forma, verifica-se que a cidade de Teresina está distante do que Lehmann (2016) denomina de "densificação com qualidade", que alia densificação com áreas de vegetação. Ou seja, os impactos da urbanização só serão vencidos, dentre outros aspectos, com estratégias de mitigação que incluam a preservação dos recursos naturais, como as áreas com cobertura vegetal. Neste sentido, 
Riffat, Powell e Aydin (2016) asseguram que para configurações urbanas sustentáveis, a saída é aliar uso eficiente dos recursos com oportunidades, desenho de cidades compactas com menores custos de urbanização e aumento das áreas vegetadas, dentre outras estratégias.

As alterações na cobertura do solo urbano por regiões, representam melhor este comportamento diferenciado, apresentando-se na Tabela 2, apenas, as categorias de Solo Urbanizado, Solo Vegetado e Exposto, desconsiderando os corpos d'agua, o que explicaria o não fechamento dos percentuais em $100 \%$.

Tabela 2 - Categorias de Cobertura do Solo, por Região, em hectare, porcentagem da área da região ocupada, para 2000, 2010 e 2015 e crescimento 2000/2015.

\begin{tabular}{|c|c|c|c|c|c|c|c|}
\hline \multirow{2}{*}{ REGIÃO } & \multirow{2}{*}{ PERÍODO } & \multicolumn{3}{|c|}{ ÁREA EM HECTARE } & \multicolumn{3}{|c|}{ PERCENTUAL REGIÃO } \\
\hline & & urbanizado & vegetado & exposto & $\%$ urb & \% veg & $\% \exp$ \\
\hline Central & 2000 & 2741,05 & 1539,23 & 271,43 & 59,68 & 33,51 & 5,51 \\
\hline \multirow[t]{2}{*}{4592,65 ha } & 2010 & 3290,57 & 1079,25 & 185,48 & 71,65 & 23,50 & 4,04 \\
\hline & 2015 & 3415,66 & 894,66 & 244,26 & 74,37 & 19,48 & 5,32 \\
\hline Crescimento & $2000 / 2015$ & 674,61 ha & $-644,57$ ha & $-27,17$ ha & $24,61 \%$ & $-41,88 \%$ & $-10,01 \%$ \\
\hline Sul & 2000 & 958,75 & 1152,88 & 332,86 & 39,18 & 47,11 & 13,60 \\
\hline \multirow[t]{3}{*}{2446,92 ha } & 2010 & 1372,41 & 882,54 & 187,28 & 56,09 & 36,07 & 7,65 \\
\hline & 2015 & 1651,22 & 673,82 & 119,81 & 67,48 & 27,54 & 4,90 \\
\hline & $2000 / 2015$ & 692,47 ha & $-479,06$ ha & $-213,05$ ha & $72,23 \%$ & $-41,55 \%$ & $-64,01 \%$ \\
\hline Extremo Sul & 2000 & 472,78 & 3203,95 & 291,51 & 11,91 & 80,71 & 7,34 \\
\hline \multirow[t]{3}{*}{3969,96 ha } & 2010 & 891,50 & 2735,94 & 340,90 & 22,46 & 68,92 & 8,59 \\
\hline & 2015 & 1590,96 & 1624,18 & 753,91 & 40,07 & 40,91 & 18,99 \\
\hline & $2000 / 2015$ & $1118,18 \mathrm{ha}$ & $-1579,80$ ha & 462,40 ha & $236,51 \%$ & $-49,31 \%$ & $158,62 \%$ \\
\hline Sudeste & 2000 & 1049,09 & 3328,29 & 180,13 & 22,98 & 72,91 & 3,95 \\
\hline \multirow[t]{3}{*}{4565,17 ha } & 2010 & 1579,58 & 2785,45 & 183,65 & 34,60 & 61,01 & 4,02 \\
\hline & 2015 & 1862,71 & 2289,20 & 403,70 & 40,80 & 50,15 & 8,84 \\
\hline & $2000 / 2015$ & 813,62 ha & $-1039,10$ ha & 223,57 ha & $77,55 \%$ & $-31,22 \%$ & $124,12 \%$ \\
\hline Leste & 2000 & 1368,37 & 3291,42 & 449,97 & 26,54 & 63,84 & 8,73 \\
\hline \multirow[t]{3}{*}{5155,86 ha } & 2010 & 2562,71 & 2272,19 & 264,87 & 49,71 & 44,07 & 5,14 \\
\hline & 2015 & 2906,54 & 1867,32 & 355,35 & 56,37 & 36,22 & 6,89 \\
\hline & $2000 / 2015$ & 1538,17 ha & $-1424,10$ ha & $-94,62$ ha & $112,41 \%$ & $-43,27 \%$ & $-21,03 \%$ \\
\hline Nordeste & 2000 & 120,03 & 1744,20 & 71,41 & 6,20 & 90,05 & 3,69 \\
\hline \multirow[t]{3}{*}{1936,81 ha } & 2010 & 382,16 & 1428,68 & 118,50 & 19,73 & 73,76 & 6,12 \\
\hline & 2015 & 530,11 & 1205,54 & 195,94 & 27,37 & 62,24 & 10,12 \\
\hline & $2000 / 2015$ & 410,08 ha & $-538,66 \mathrm{ha}$ & $124,53 \mathrm{ha}$ & $341,65 \%$ & $-30,88 \%$ & $174,39 \%$ \\
\hline Norte & 2000 & 190,96 & 2824,35 & 263,48 & 5,77 & 85,37 & 7,96 \\
\hline \multirow[t]{3}{*}{3308,47 ha } & 2010 & 614,92 & 2281,23 & 389,23 & 18,59 & 68,95 & 11,76 \\
\hline & 2015 & 945,78 & 1259,32 & 1084,78 & 28,58 & 38,07 & 32,79 \\
\hline & $2000 / 2015$ & 754,82 ha & $-1565,03$ ha & 821,30 ha & $395,28 \%$ & $-55,41 \%$ & $311,71 \%$ \\
\hline
\end{tabular}

Fonte: Imagens Landsat, USGS (2000, 2010, 2015); TERESINA (2015a), processados no SPRING e ArcGIS (10.3).

Os espaços urbanizados que apresentaram maior crescimento territorial foram as regiões Leste, com 5.155,86 hectares, a Central, com 4.592,65 hectares, e a Sudeste, com 4.565,17 hectares. E na sequência tem-se a região Extremo Sul, com 3.969,96 hectares, Norte com 3.308,47, Sul com 2.446,92, e a Nordeste com 1.936,81 hectares.

As regiões com as taxas proporcionais mais elevadas de solo urbanizado, em 2015, em relação às suas áreas territoriais, foram as regiões, Central, com 74,37\%, depois a Sul, com $67,48 \%$, e a Leste, com 56,37\%. E as com menores percentuais de solos urbanizados foram as regiões, Nordeste, com $27,37 \%$, vindo a seguir a Norte, com 28,58\%. As regiões do Extremo Sul e Sudeste apresentaram 40,07\% e 40,80\%, respectivamente de área urbanizada.

Justamente, as regiões que apresentaram menores percentuais de solo urbanizado foram as que mais cresceram proporcionalmente entre 2000 e 2015, região Norte (395,28\%), Nordeste (341,65\%) e Extremo Sul (236,51\%). Territorialmente, as regiões que mais aumentaram os solos urbanizados foram as regiões Leste (1.538,17 hectares), Extremo Sul (1.118,18 hectares), Sudeste (813,62 hectares) e Norte (754,82 hectares). E as regiões com os menores acréscimos no percentual de solo urbanizado, entre 2000 e 2015 , foram as regiões Central (24,61\%), Sul (72,23\%) e Sudeste $(77,55 \%)$. As maiores perdas de cobertura de solo 
vegetal foram detectadas nas regiões Norte $(55,41 \%)$, Extremo Sul $(49,31 \%)$ e Leste $(43,27 \%)$.

Observa-se que, entre as regiões consolidadas Central, Sul, Sudeste e Leste, o crescimento mais expressivo de solo urbanizado ocorreu na região Leste, enquanto nas regiões de urbanização mais recente, Norte, Nordeste e Extremo Sul, esta expansão do solo urbanizado foi mais expressiva proporcionalmente, sendo a redução de solo vegetado e o aumento do solo exposto, mais perceptível (Figura 6).

Figura 6 - Gráfico de cobertura de solos de Teresina por regiões

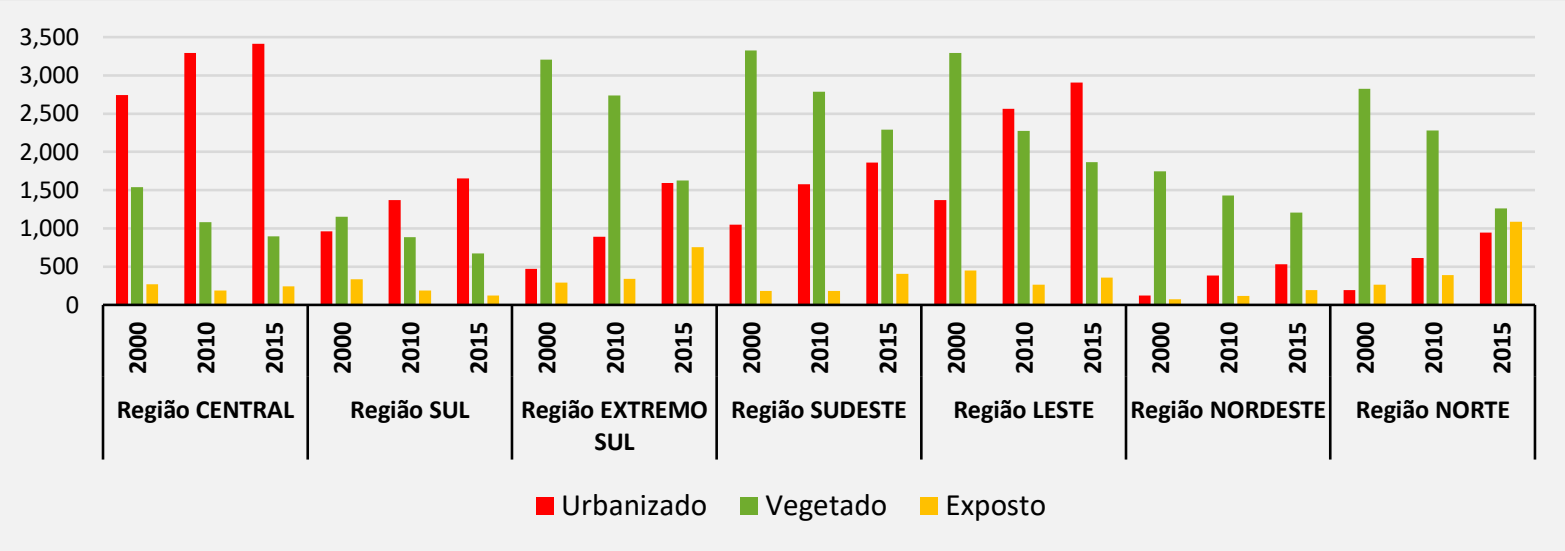

Fonte: Imagens LANDSAT 7_TM e LANDSAT 8_OLI, USGS (2000, 2010 e 2015), TERESINA (2015a), trabalhados no SPRING e ArcGIS (10.3).

As regiões Extremo Sul e Norte, além da redução na cobertura com vegetação, as áreas de solo exposto dobraram em tamanho, no período entre 2010 e 2015. Estas regiões de Teresina, localizadas nos dois extremos da zona urbana, apresentaram nos últimos anos, maior volume de investimentos públicos em habitações de origem municipal, com a implantação de vários conjuntos populares.

Destaca-se, na região Norte, a construção do conjunto Habitacional Jacinta Andrade, com investimentos provenientes do governo Federal e executado pela Agência de Desenvolvimento Habitacional do Piauí (ADH), com 4.000 unidades habitacionais, localizado a $15 \mathrm{~km}$ do centro de Teresina.

Sperandelli, Dupas e Pons (2013) e Nadalin e Igliori (2015) observaram "a periferização da pobreza" ligada à expansão urbana e a desigualdade socioespacial, já que os altos preços das áreas bem servidas de infraestrutura, a retenção de terrenos para especulação, empurram as famílias de baixa renda para longe destes espaços providos de serviços básicos.

Foi constatado que, na cidade de Teresina, já se encontra quase $50 \%$ de espaços impermeabilizados e menos de $40 \%$ de solos apresentam cobertura vegetal. E, do total de 10.046,34 hectares de solos vegetados encontrados para 2015, as áreas livres públicas, entre praças, parques, Zoobotânico, Centro de Ciências Agrárias da Universidade Federal do Piauí (UFPI), Empresa Brasileira de Pesquisa Agropecuária (EMBRAPA) e Jardim Botânico, somam 864,8 hectares (TERESINA, 2013).

A "densificação com qualidade", equilíbrio entre urbanização e áreas verdes, sugeridas por Lehmann (2016) e Riffat, Powell e Aydin (2016) como passos importantes na conquista da sustentabilidade urbana, são realidades distantes para Teresina. Na Tabela 4 estão apresentados dados de densidade populacional e de domicílio, para Teresina, considerando os anos de 2000 e 2010.

Tabela 4 - Densidade populacional e de domicílio para Teresina 2000 e 2010, baseado em imagens

\begin{tabular}{cccccc}
\hline TERESINA & $\begin{array}{c}\text { POPULAÇÃOO } \\
\text { URBANA }\end{array}$ & $\begin{array}{c}\text { DOMICILIO } \\
\text { URBANO }\end{array}$ & $\begin{array}{c}\text { SOLOS } \\
\text { URBANIZADOS } \\
\text { (hectare) }\end{array}$ & $\begin{array}{c}\text { DENSIDADE } \\
\text { POPULACIONAL } \\
\text { (hab/ha) }\end{array}$ & $\begin{array}{c}\text { DENSIDADE } \\
\text { DOMICILIAR } \\
\text { (dom/ha) }\end{array}$ \\
\hline 2000 & 677.470 & 162.494 & $7.003,08$ & 96,74 & 23,20 \\
2010 & 767.557 & 210.270 & $10.759,68$ & 71,34 & 19,54 \\
\hline
\end{tabular}

Fonte: IBGE (2000a, 2010a), TERESINA (2015a), Imagens LANDSAT 7_TM, USGS (2000; 2010), trabalhados no SPRING e ArcGIS (10.3). 
Com base nas densidades médias encontradas, de 29,06 hab/ha, bem abaixo do recomendado para se ter uma distribuição eficiente de infraestrutura, que segundo Mascaró e Mascaró (2001) deve ser no mínimo 40 hab/ha, estima-se que estes dados de espaços livres públicos e cobertura vegetal, apresentadas em Teresina, apontam para uma cidade, cada vez mais espraiada, com maior impermeabilização de solos, o que traz dúvidas quanto ao futuro destes espaços.

Outro aspecto que evidencia o processo de espraiamento é a redução na densidade líquida, aquela que se refere à relação entre dados populacionais e apenas áreas ocupadas, entre 2000 e 2010, em Teresina, de acordo com as imagens de satélite. Observando-se apenas a área territorial ocupada pelos solos urbanizados e considerando, somente, a população urbana de Teresina, as densidades líquidas, passaram de uma situação de 96,74 hab/ha, em 2000, para 71,34 hab/ha, em 2010.

\section{CONSIDERAÇÕES FINAIS}

Pensar em sustentabilidade urbana implica, entre outros aspectos, em reflexões sobre como uma população usa os espaços de forma equilibrada, eficiente e responsável, buscando a melhoria de todos, agora e no futuro. Dentre as possibilidades de sustentabilidade, apontadas na literatura, a "densificação com qualidade" seria uma delas, em que, a urbanização deve andar junto com densificação e aumento das áreas verdes.

A cidade de Teresina apresenta acelerado processo de expansão urbana, que se configura mais como espraiado do que compacto, havendo consumo de solos bem superior ao crescimento de sua população e sem equilíbrio entre solos impermeabilizados e solos vegetados.

Em relação à vegetação existente, um fato preocupante, é que do total da cobertura de solo vegetal, apenas, menos de $10 \%$ do que existe, é assegurado como pública e de preservação, trazendo incertezas quanto ao destino da maioria deste tipo de cobertura de solo.

Entre as regiões teresinenses, as já consolidadas (Central, Sul, Sudeste e Leste), apresentaram um crescimento de solo urbanizado menor que as demais regiões, de urbanização mais recente (Norte, Nordeste e Extremo Sul). Nas regiões consolidadas, o crescimento de solo urbanizado, ficou mais visível nos núcleos, enquanto nas demais regiões, foram nas franjas onde houve maior acréscimo de solo urbanizado. Entre as regiões consolidadas de Teresina, os territórios urbanos em que se observou maior expansão de solos urbanizados, foram os situados nas regiões Leste e Sudeste e, dentre as regiões de urbanização mais recentes destacam-se os territórios no Extremo Sul e Norte.

Nas regiões Leste e Central, que apresentam as mais altas rendas, são onde se encontram os espaços que possuem melhor atendimento de serviços públicos. Nas demais regiões, principalmente, aquelas habitadas por populações de renda média abaixo de três salários mínimos, é onde o acesso a serviços públicos são mais precários.

A impermeabilização de vastas áreas de solo urbano em Teresina, somada às grandes perdas e distribuição desigual de sua cobertura vegetal, indicam que o processo de urbanização não está acontecendo de forma sustentável, já que a urbanização não caminha junto com o aumento das áreas de vegetação. Estes aspectos são preocupantes diante das possibilidades futuras destes solos, pois estes resultados apontam que a legislação vigente não está garantindo a preservação e seus usos em favor de toda a cidade e de sua população.

\section{REFERÊNCIAS}

ALTUNKASA, M. F., BERBEROĞLU, S., USLU, C., DUYMUŞ, H. The effectiveness of urban green spaces and socio-cultural facilities. Journal of Land Use, Mobility and Environment, v.10, n 1, p. 41-56, 2017. http://dx.doi.org/10.6092/1970-9870/4087.

ANDRADE, C. S. Teresina e clima: Indissociabilidades no estudo da cidade. Equador. v. 5, n. 3, (Edição Especial 02), p.398 - 420 , 2016. http://www.ojs.ufpi.br/index.php/equador).

BRASIL. Presidência da República. Decreto $\mathbf{n}^{\mathbf{0}}$ 4.367, de 9 de setembro de 2002. Brasília, 2002. Disponível em: http://www.planalto.gov.br/ccivil_03/decreto/2 002/d4367.htm. Acesso em: 28 de out. 2016.

CATALÁN, B; SAURI, D.; SERRA, P. Urban sprawl in the Mediterranean? Patterns of growth and change in the Barcelona Metropolitan Region 1993-2000. Landscape and Urban Planning. v. 85, p. 174-184, 2008.

https://doi.org/10.1016/j.landurbplan.2007.11. 004.

FEITOSA, S. M. R.; GOMES, J. M. A.; MOITA NETO, J. M.; ANDRADE, C. S. P. de. 
Consequências da Urbanização na Vegetação e na Temperatura da Superfície de Teresina, Piaui. REVSBAU, Piracicaba, SP, v. 6, n. 2, p. 58-75, 2011. http://dx.doi.org/10.5380/revsbau.v6i2.66395.

GAROTTI, L. M.; BARBASSA, A. P. Estimativa de área impermeabilizada diretamente conectada e sua utilização como coeficiente de escoamento superficial. Engenharia Sanitária e Ambiental. v. 15, n.1, p. 19-28, jan./mar. 2010. https://doi.org/10.1590/S141341522010000100003.

IBGE, Instituto Brasileiro de Geografia e Estatística, Cidades e Estados: Teresina, 2020. Disponível em: https://www.ibge.gov.br/cidades-e-

estados/pi/teresina.html. Acesso em: $17 \mathrm{dez}$. 2020.

IBGE, Instituto Brasileiro de Geografia e

Estatística, 2015. População

Estimada_2015. Disponível em:

www.ibge.gov.br/home/estatistica/população/e stimativa2015/estimativa_tcu.shtm. Acesso em: 07 out. 2016

IBGE, Instituto Brasileiro de Geografia e Estatística, 2010a. Censo 2010_População. Disponível

em: http://ibge.gov.br/home/estatistica/populacao/c enso2010/default_resultados_universo.shtm.

Acesso em: 28 jan. 2017.

IBGE, Instituto Brasileiro de Geografia e Estatística, 2010b. Censo 2010_Agregados por Setores Censitários. Disponível em: https://ibge.gov.br/Censos/Censo_Demografico _2010/Sinopse/Agregados_por_Setores_Censit arios/. Acesso em: 28 jan. 2017.

IBGE, Instituto Brasileiro de Geografia e Estatística, 2010c. Malha Digital de Setores Censitários. Disponível em: http://downloads.ibge.gov.br/downloads_geoci encias.htm. Acesso em: 28 jan. 2017.

IBGE, Instituto Brasileiro de Geografia e Estatística, 2000a. Censo 2000_População. Disponível

em:

http://ibge.gov.br/home/estatistica/populacao/c enso2000/default.shtm. Acesso em: 28 jan. 2017.

IBGE, Instituto Brasileiro de Geografia e Estatística, 2000b. Censo 2000_Agregado por Setor Censitário. Disponível em: http://ibge.gov.br/home/estatistica/populacao/ defaulttab_agregado.shtm. Acesso em: 28 jan. 2017.

IBGE, Instituto Brasileiro de Geografia e Estatística, 2000c. Malha Digital de Setores Censitários. Disponível em: http://downloads.ibge.gov.br/downloads_geoci encias.htm. Acesso em: 28 jan. 2017.
INOSTROZA, L.; BAUR, R.; CSAPLOVICS, E. Urban sprawl and fragmentation in Latin America: A dynamic quantification and characterization of spatial patterns. Journal of Environmental Management. v. 115, p. 87-97, 2013. https://doi.org/10.1016/j.jenvman.2012.11.007. KEMERICH, P. D. C.; MARTINS, S. R.; KOBIYAMA, M.; FLORES, C. E. B.; BORBA, W. F. de; FERNANDES, G. D.; SANTI, A. L.; CHERUBIN, M. R. Infiltração e Escoamento Superficial sob Diferentes Usos e Ocupação em uma Bacia Hidrográfica. Anuário do Instituto de Geociências. v. 37, n. 2, p. 7588, 2014. http://dx.doi.org/10.11137/2014_2_75_88.

LEHMANN, S. Sustainable urbanism: towards a framework for quality and optimal density? Future Cities and Environment. v. 2, n. 8, p. 1-13, 2016. http://doi.org/10.1186/s40984016-0021-3.

LIMA, I. M. M. F. Teresina: Urbanização e Meio Ambiente. Scientia et Spes, v.1, n. 2, p.181206, 2002.

LIMA, S. M. S. A.; LOPES, W. G. R.; FAÇANHA, A. C. Urbanização e crescimento populacional: reflexões sobre a cidade de Teresina, Piauí. Gaia Scientia, v. 1, n. 1, p. 31-51, 2017. http://dx.doi.org/10.21707/gs.v11.n01a3.

LONDE, P. R.; MENDES, P. C. A influência das áreas verdes na qualidade da vida urbana. HYGEIA, Revista Brasileira de Geografia Médica e da Saúde. v. 10, n. 18, p. 264-272, 2014.

MACHADO, R. R. B.; PEREIRA, E. C. G.; ANDRADE, L. H. C. Evolução Temporal (20002006) da Cobertura Vegetal na Zona Urbana do Município de Teresina, Piauí, Brasil. REVSBAU, v. 5, n. 3, p. 97-112, 2010. http://dx.doi.org/10.5380/revsbau.v5i3.66307.

MASCARÓ, J. J.; MASCARÓ, L. Densidades, ambiência e infraestrutura urbana. Arquitextos. ano 02, n. 017.08, out. 2001.

MORATO, R. G.; KAWAKUBO, F. S.; HAYAKAWA, E. H.; MACHADO, R. P. P. Análise da Expansão Urbana por Meio de Composições Coloridas Multitemporais. Mercator, Fortaleza, v. 10, n. 22, p. 221-231, maio/ago.

2011. https://doi.org/10.4215/RM2011.1022.0014.

MOURA, A. R.; NUCCI, J. C. Cobertura Vegetal em Áreas Urbanas: O Caso do bairro de Santa Felicidade, Curitiba, PR. Geografia. Ensino \& Pesquisa, v. 12, p. 1682-1698, 2008.

NADALIN, V.; IGLIORI, D. Espraiamento urbano e periferização da pobreza na região metropolitana de São Paulo: evidências empíricas. EURE, v. 41, n. 124, p. 91-111, set. 
$2015 . \quad$ http://dx.doi.org/10.4067/S025071612015000400005.

REIS FILHO, A. A. Análise Integrada por geoprocessamento da expansão urbana de Teresina com base no Estatuto da Cidade: estudo de potencialidades, restrições e conflitos de interesses. 2012, 278 f., Tese (Doutorado em Geografia), Universidade Federal de Minas Gerais, Belo Horizonte, 2012.

RIFFAT, S.; POWELL, R.; AYDIN, D. Future cities and environmental sustainability. Future Cities and Environment. v. 2, n. 1, 2016. http://doi.org/10.1186/s40984-016-00142.

ROCHA, M. F.; NUCCI, J. C. Cobertura vegetal na região central das capitais brasileiras. GEOgraphia. v. 21, n. 45, jan./abr., 2019. https://doi.org/10.22409/GEOgraphia2019.v21 i45.a14352.

SANTOS, J. LANDSAT-8: Download de imagens através dos sites Earth Explorer e GLOVIS, 2013. Processamento Digital Geotecnologias e Software Livre. Disponível em: http://www.processamentodigital.com.br/wpcontent/uploads/2013/08/20130531_Landsat8_ download_USGS.pdf. Acesso em 20 de agosto de 2020.

SETO, K. C. et al. A Meta-Analysis of Global Urban Land Expansion. PLoS ONE. v. 6, n. 8, 2011.

https://doi.org/10.1371/journal.pone.0023777. SPERANDELLI, D.; DUPAS, F. A.; PONS, N. A. D. Dynamics of Urban Sprawl, Vacant Land, and Green Spaces on the Metropolitan Fringe of São Paulo, Brazil. Journal of Urban Planning and Development, v. 139, p. 274$279 . \quad$ Dec. 2013. https://doi.org/10.1061/(ASCE)UP.1943-

5444.0000154.

STREGLIO, C. F. C.; FERREIRA, D. T.; OLIVEIRA, I. J. O Processo de Expansão Urbana e seus Reflexos na Redução da Cobertura Vegetal no Município de GoiâniaGO. RA'EGA, n. 28, p. 181-197, 2013. http://dx.doi.org/10.5380/raega.v28i0.32306.

TERESINA: Secretaria Municipal de Desenvolvimento Econômico e Turismo (SEMDEC). 2010. Perfil de Teresina: Econômico, Social, Físico e Demográfico. Teresina: Secretaria Municipal de Desenvolvimento Econômico e Turismo (SEMDEC). 2010.
TERESINA, Prefeitura Municipal de Teresina, 2013. Plano Plurianual 2013/2014. Lei n 4.483/2013. Anexo II - Diagnóstico e Perspectiva Econômica. Disponível em: http://www.teresina.pi.gov.br/sistemas/domwe b/admin/upload/DOM1581-A-19122013.pdf.

Acesso em: 17 jan. 2017.

TERESINA, Secretaria Municipal de Planejamento e Coordenação, SEMPLAN, 2015a. Mapas de Teresina. Disponível em: https://semplan.pmt.pi.gov.br/mapasinterativos/. Acesso em: 28 dez. 2020.

TERESINA, Prefeitura Municipal de Teresina. Lei ${ }^{\circ} 4.831$, de 26 de outubro de 2015. Dispõe sobre a delimitação do perímetro da zona urbana de Teresina e dá outras providências 2015b. Diário Oficial do Município Legislação Urbana. Ano 2015, n. 1828. Disponível em: http://200.23.153.37/acervodigital/norma/lei4831-2015. Acesso em: 20 abr. 2021.

USGS, Science For A Changing World. Earth Resources Observation and Science Center. Disponível em: https://www.usgs.gov/science/missionareas/climate-and-land-use-change/earthresources-observation-and-science-center. Acesso em: 15 nov. 2016.

ZHAO, J.; CHEN, S.; JIANG, B.; REN, Y.; WANG, H.; VAUSE, J.; YU, H. Temporal trend of green space coverage in China and its relationship with urbanization over the last two decades. Science of the Total Environment, v. 442, p. 455-465, 2013. https://doi.org/10.1016/j.scitotenv.2012.10.014

ZHOU, X.; WANG, Y. Spatial-temporal dynamics of urban green space in response to rapid urbanization and greening policies. Landscape and Urban Planning. v. 100, n. 3, p. 268-277, 2011. https://doi.org/10.1016/j.landurbplan.2010.12. 013.

\section{CONTRIBUIÇÃO DO AUTOR}

Silvia Maria Santana Andrade Lima concebeu o estudo, coletou, analisou os dados e redigiu o texto. Wilza Gomes Reis Lopes participou da elaboração do estudo e da leitura, discussão e correção do texto. Antonio Cardoso Façanha colaborou na leitura e discussão do texto.

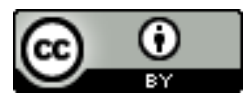

Este é um artigo de acesso aberto distribuído nos termos da Licença de Atribuição Creative Commons, que permite o uso irrestrito, distribuição e reprodução em qualquer meio, desde que o trabalho original seja devidamente citado. 